\title{
High-risk electrocardiogram patterns in patients with syncope managed in the emergency department
}

\author{
Marco Tomaino, ${ }^{1}$ Matthias Unterhuber, ${ }^{1}$ Attilio Del Rosso ${ }^{2}$ \\ ${ }^{1}$ Regional Hospital of Bolzano; ${ }^{2}$ Regional Hospital of Empoli, Italy
}

\section{Introduction}

The Electrocardiogram (ECG) plays a crucial role in initial syncope evaluation. After a careful clinical history evaluation and an accurate physical examination including supine and standing BP measurements, the ECG features represent a pivotal moment to stratify the risk of patients. The presence of ECG findings suggesting arrhythmic syncope put the patient at relevant risk. This could mean the necessity to perform further specific invasive and noninvasive diagnostic procedures (echocardiogram, effort test, ECG monitoring, transoesophageal study, electrophysiological study, external and implantable loop recorder, magnetic resonance, coronary angiography). Furthermore, some ECG features already represent an indication for a therapeutic strategy (pharmacological treatment, radio-frequency ablation or device implantation like pacemaker and permanent autonomous defibrillator) (Tables 1 and 2). ${ }^{1-9}$ On one hand a normal $E C G^{1-4}$ with no pathological findings in clinical evaluation stratifies the syncopal events at low risk, on the other hand ECG findings can represent red flags in identifying high-risk patients. ${ }^{5}$

\section{Sinus bradycardia, recurrent sinoatrial block and prolonged sinus arrest}

The first important aspect to interpret correctly the ECG is the

\author{
Correspondence: Marco Tomaino, Regional Hospital of Bolzano, Via \\ Lorenz Böhler 5, 39100 Bolzano, Italy \\ E-mail: marco.tomaino@sabes.it \\ Key words: High-risk electrocardiogram patterns; Syncope; emergency \\ department. \\ Contributions: the authors contributed equally. \\ Conflict of interest: the authors declare no potential conflict of interest. \\ Funding: none. \\ Received for publication: 18 May 2018. \\ Revision received: 29 June 2018. \\ Accepted for publication: 29 June 2018. \\ This work is licensed under a Creative Commons Attribution 4.0 \\ License (by-nc 4.0) \\ CC Copyright M. Tomaino et al., 2018 \\ Licensee PAGEPress, Italy \\ Emergency Care Journal 2018; 14:7570 \\ doi:10.4081/ecj.2018.7570
}

recognition of sinus rhythm (SR). The depolarization wave of SR has an electric axis of approximately $60^{\circ}$ and is positive in D1. Every $\mathrm{P}$ wave is followed by a QRS complex with constant PQ interval. Figure 1A shows a bradycardic SR with a heart rate (HR) of $45 \mathrm{bpm}$, which should be interpreted in the context of the clinical features of the patient: in athletes, this condition represents the normality. In some case further diagnostic investigation is needed.

Clinical advice: effort test to verify the appropiate increase of HR (chronotropic competence) and the AV conduction. Echocardiogram for the exclusion of an organic cardiomyopathy; sinus node recovery time $(\mathrm{SNRT})^{10}$ and nodal AV system (Wenckebach point and 1:1 AV conduction) ${ }^{11}$ using a simple transoesophageal study. It is not necessary to perform an invasive electrophysiological study.

Clinical advice (Figure 1B): this is a clear example of significant sinus bradycardia which represents in most cases an accepted indication for cardiac pacing in a patient with syncope.

Clinical advice (Figure 1C): investigate sinus node function with transoesophageal electrophysiological study (EPS) or invasive EPS.

Clinical advice (Figure 1D): this is an indication for cardiac pacing in patients with syncope.

Clinical advice (Figure 1E): this diagnosis in a patient affected by syncope is almost always treated using a pacemaker implantation in addition to pharmacological antiarrhythmic prophylaxis. ${ }^{12-16}$

\section{Second and third degree atrio-ventricular block: bundle branch blocks}

Bundle branch conduction disturbances reflect a deficiency which involves the part of the system under the AV node (infrahis system) (Figure 2).

In patients affected by syncope the evidence of BBB is highly suggestive for cardiac syncope. Second degree AV block Mobitz 2, third degree AV block and alternating bundle branch blocks (BBB) are a clear indication for cardiac pacing. Patients with syncope and left bundle branch block, right bundle branch block, left anterior hemiblock or 2nd degree AV block Mobitz 1 (LucianiWenckebach) must undergo further diagnostic investigation. ${ }^{17-23}$

Clinical advice (Figure 3A): in patients with unexplained syncope and left bundle brunch block (LBBB) at basal ECG an invasive electrophysiological study must be performed: the presence of a prolonged infrahis interval ( $\mathrm{HV}>70 \mathrm{~ms})$ stratifies to a high risk to develop a third degree AV block. Pacemaker implantation is indicated. Typical ECG features of left bundle brunch block are the large QRS complex (more than 120ms), RR' aspect in V6 derivation.

Clinical advice (Figure 3B): invasive electrophysiological study. The final report is: atrial fibrillation with aberrant AV conduction characterized by right bundle brunch block (RBBB) and left anterior hemiblock, in sum bifascicular block.

Clinical advice (Figure 3C): in a patient with syncope this finding is a clear indication to permanent cardiac pacing. The 4th $\mathrm{P}$ - 
wave is not followed by a QRS complex, there is a sudden AV block without progressive elongation of PR interval in the beats before. The AV block Mobitz 2 is related to a serious disorder of the infrahis system and results in a worse prognosis for development of total AV block.

Clinical advice (Figure 3D): a patient with syncope and these ECG features should undergo a thorough diagnostic investigation (effort test, electrophysiological study) in order to decide for permanent cardiac pacing. This condition is an AV node difficulty to conduct all beats, and is characterized by a progressive elongation

A

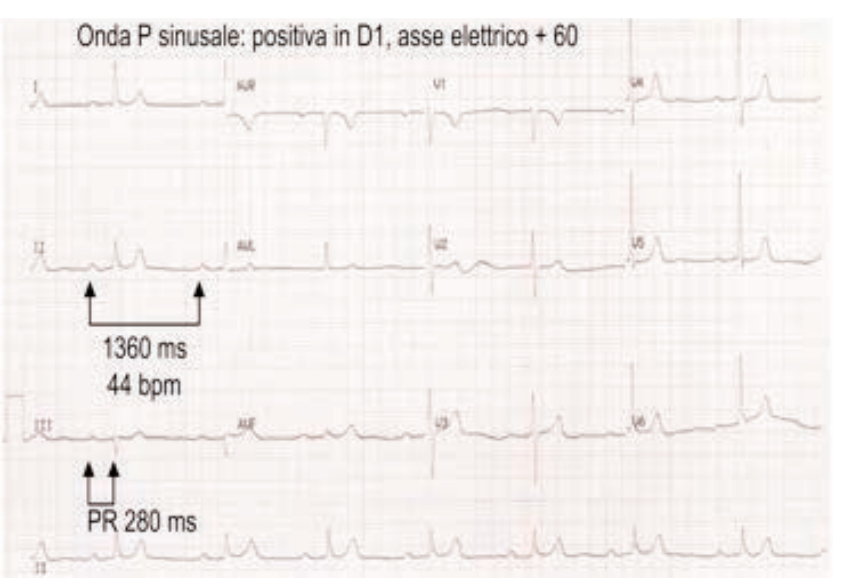

C

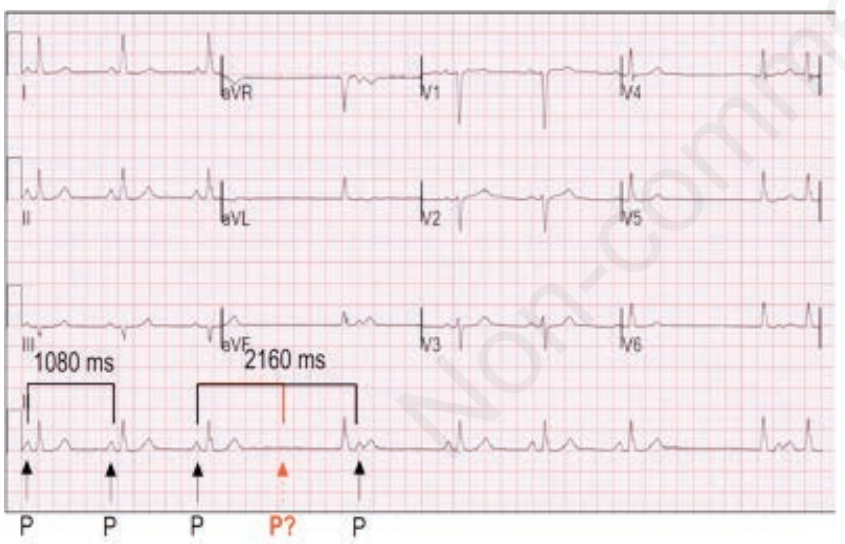

$\mathbf{E}$

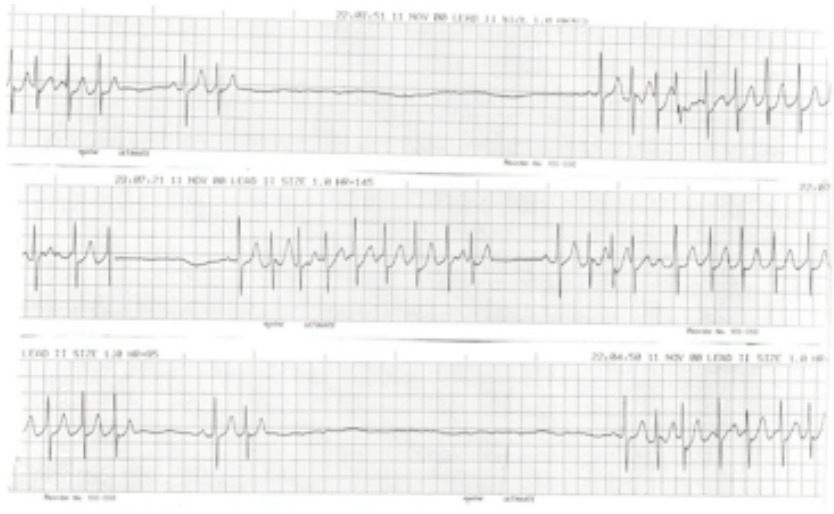

of PR interval before the AV block. Basal ECG shows SR, narrow QRS, PR 200ms and evidence of second degree AV block LucianiWenckebach (LW) or Mobitz 1-type.

Clinical advice (Figure 3E): alternating BBB is an indication for cardiac pacing irrespective of syncope. In this ECG you can see an alternating $\mathrm{LBBB}$ and RBBB. On top, confirming the important infrahis system disorder in presence of a $2^{\text {nd }}$ degree $A V$ block Mobitz 2.

Clinical advice (Figure 4 A): Pacemaker implantation.

Clinical advice (Figure 4B and C): E.v. Atropine will block

\section{B}

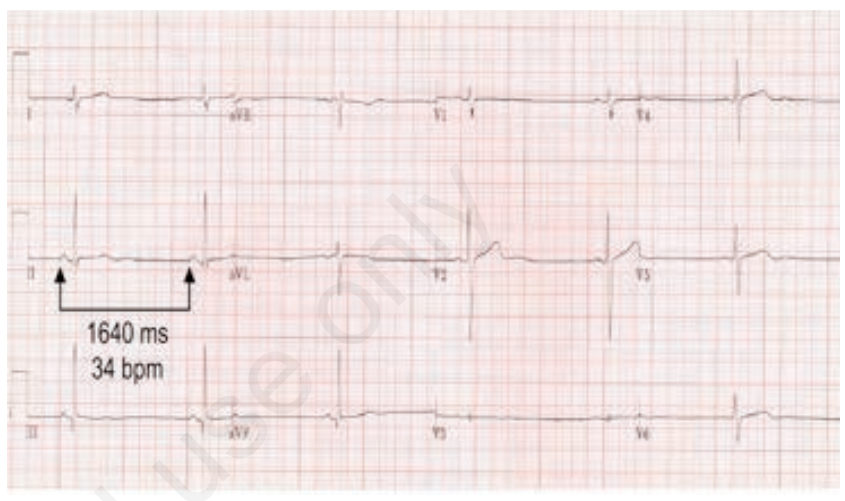

D

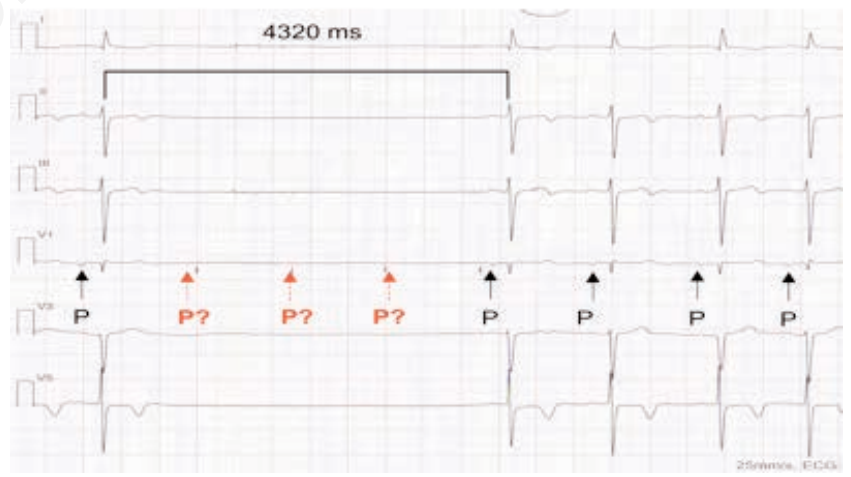

Figure 1. A) Observe the prolonged PR interval $(280 \mathrm{~ms})$; the upper limit is $200 \mathrm{~ms}$, thus representing an atrioventricular (AV) block first degree. Considering the narrow QRS complex, the most probable hypothesis is an AV node delay; B) In patients affected by syncope the evidence of a sinus bradycardia with $\mathrm{HR}<40 \mathrm{bpm}$ in waking hours is highly suggestive for arrhythmic syncope; C) Sinoatrial block. Note the missing beat at the end of the $\mathbf{P}$-wave cycle (expected beat), in absence of a significant pause $(<3 \mathrm{sec})$; D) Sinoatrial block with 4 missing beats and resultant significant pause $(>3 \mathrm{sec})$; E) Evidence of significant asystolic pause due to sinus arrest and concomitant atrial fibrillation with high ventricular response rate, i.e. brady-tachy Syndrome. In patients affected by syncope the evidence of recurrent sinus atrial block and sinus pauses $>3 \mathrm{~s}$ is highly suggestive of arrhythmic syncope. ${ }^{13-16}$ 
parasympathetic efferents thus increasing temporarily the AV conducting ability.

Clinical advice (Figure 4D): Being an infrahis conducting tissue disturbance, atropine will not increase the heart rate. By blocking parasympathetic efferents it has no effect on the infrahis system (which is not influenced by the parasympathetic nervous system).

\section{Paroxysmal supraventricular and ventricular tachycardia}

Paroxysmal supraventricular tachycardia (SVT) is an episodic condition with abrupt onset and termination. It requires underlying atrial and/or AVN and/or Wolff-Parkinson-White (WPW) conditions. In patients with a syncope the suspected SVT must be inves-

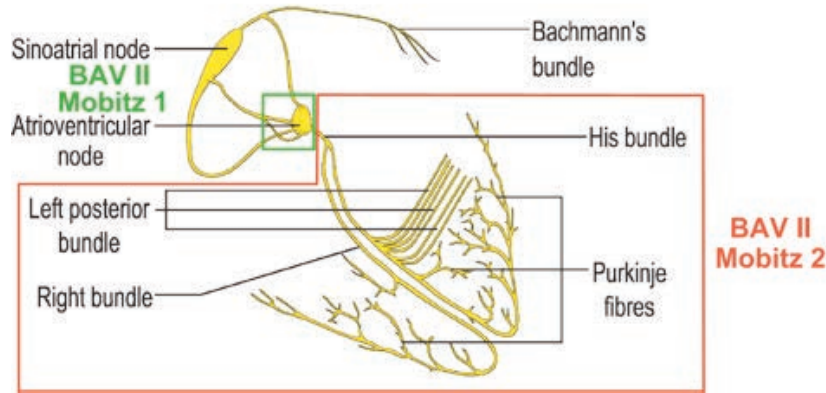

Figure 2. Bundle branch conduction disturbances reflect a deficiency which involves the part of the system under the AV node (infrahis system). Taken from: https://en.wikipedia.org/ wiki/Bundle_of_His\#/media/File:Conductionsystemoftheheartw ithouttheHeart-en.svg
A

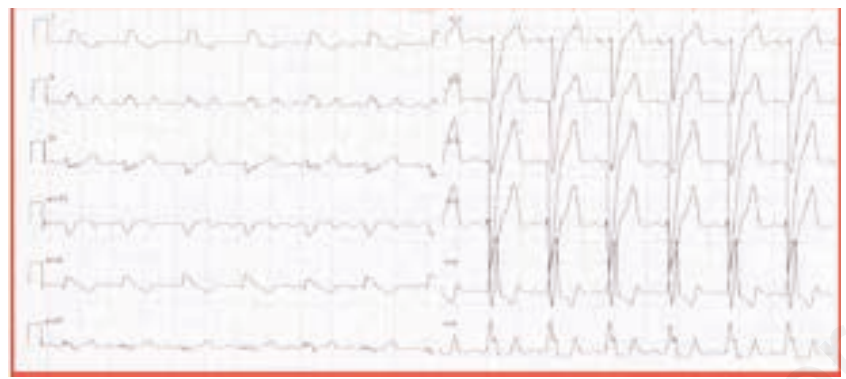

C

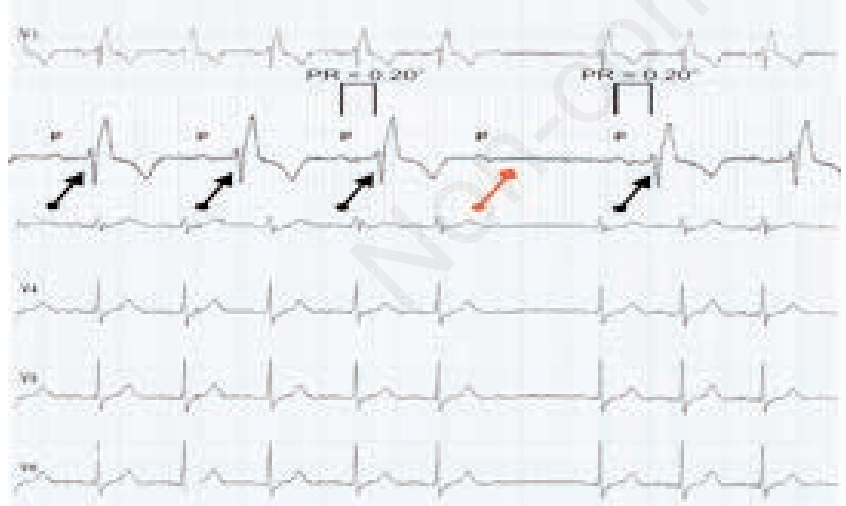

$\mathbf{E}$

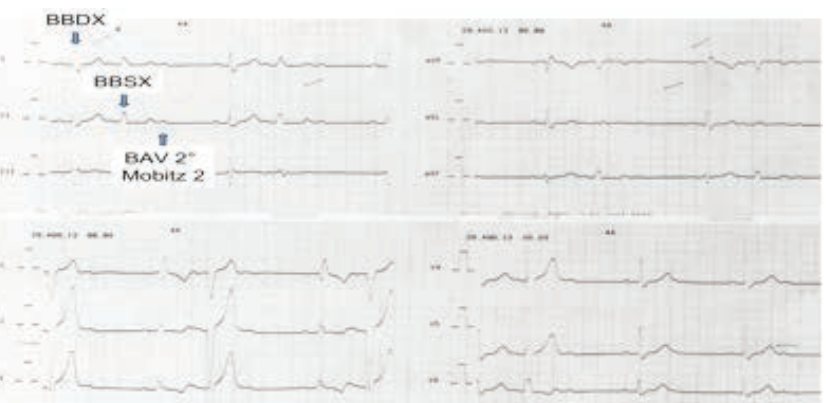

B

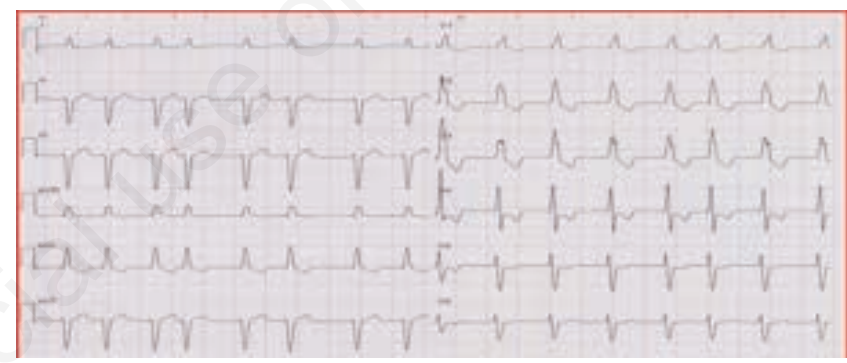

D

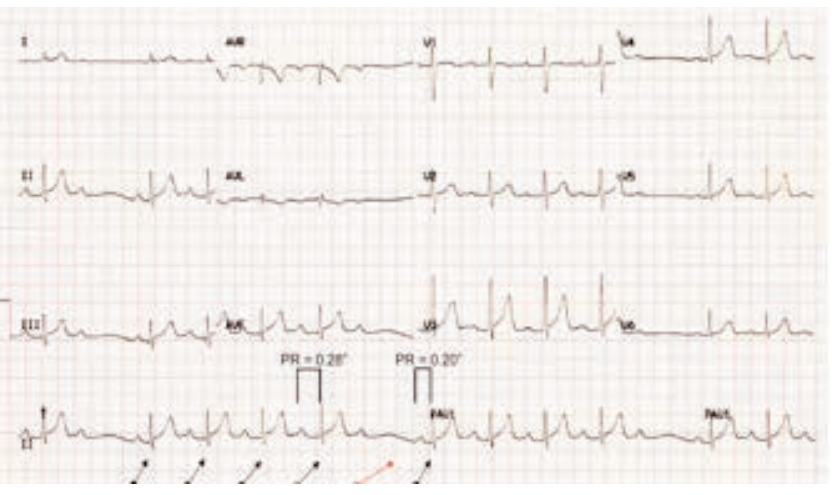

Figure 3. A) SR characterized by normal AV conduction with a left bundle branch block; B) the bundle branch abnormality concerns the right bundle (tipical ECG aspect of RR' in V1 derivation) and the left anterior branch (negative D2 and D3 that means left axis deviation $>30^{\circ}$, and deep $s$ of ventricular complex in V6 derivation). Observe the absence of the P-wave and the irregularity of ventricular beats; $\mathrm{C}$ ) dangerous manifestation of second degree AV block Mobitz type 2, in a patient with RBBB in the basal ECG and an upper limit PR interval (200msec); D) Second degree AV block related to a good prognosis; E) Very serious AV abnormality, to be considered as a prelude to total AV block. 
A

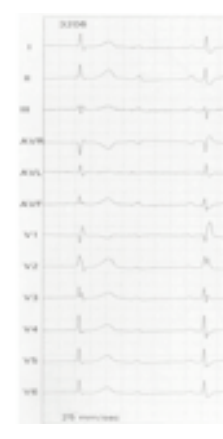

B

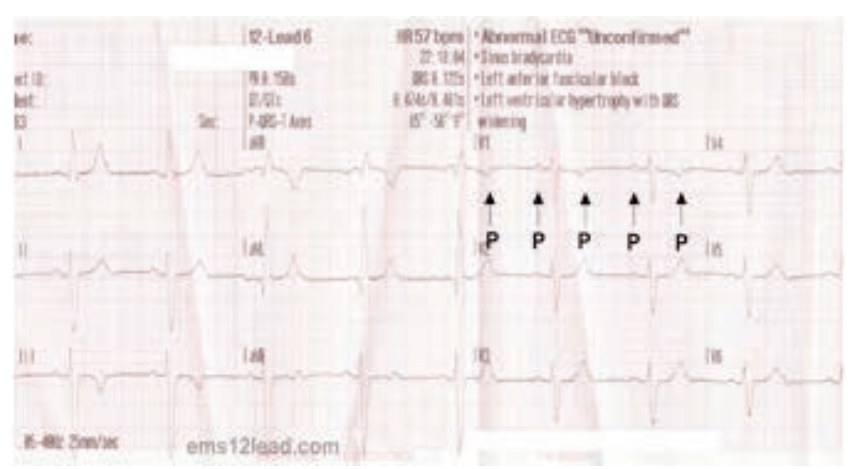

D

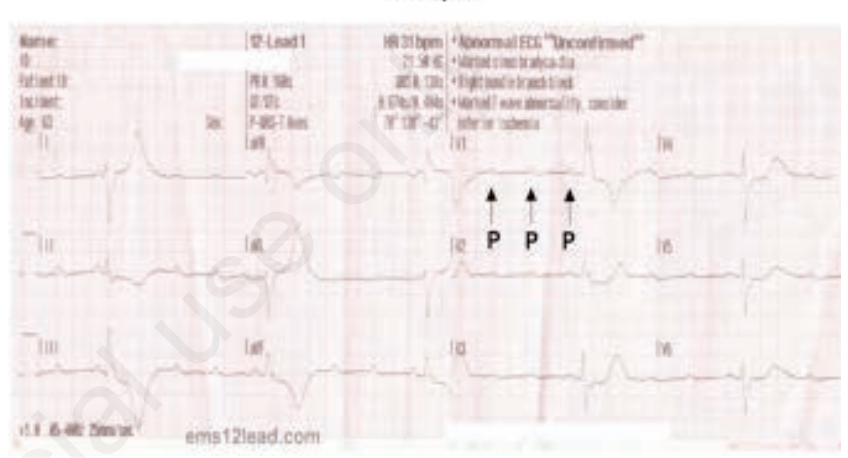

Figure 4. A) This ECG was recorded 24 hours later in the same patient: 3rd degree AV block, in which notice the complete dissociation between P-waves and QRS-complexes; B) AV-Block II' ${ }^{\circ}$ Type I Luciani-Wenckebach. before atropine; C) AV-Block II $^{\circ}$ Type I LucianiWenckebach. afterwards atropine; D) AV-Block II ${ }^{\circ}$ Mobitz II.

A

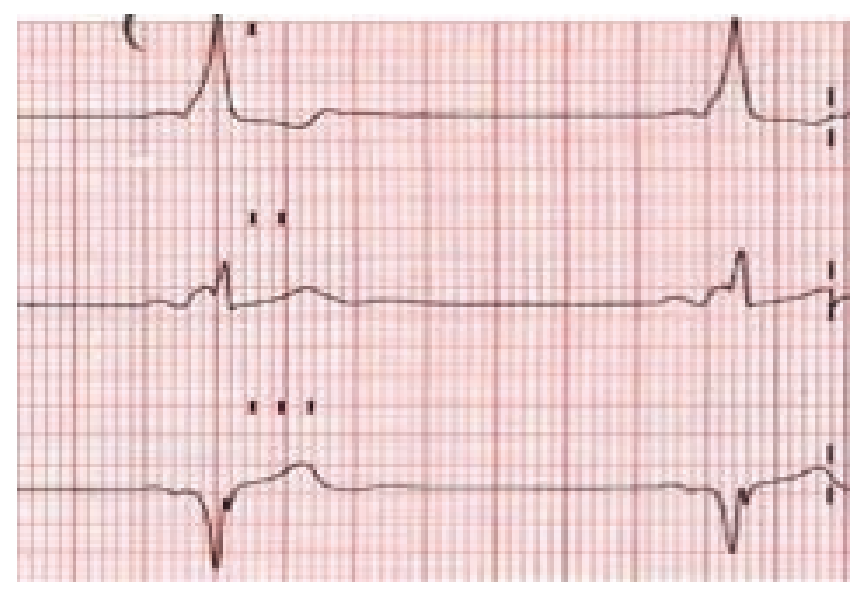

B

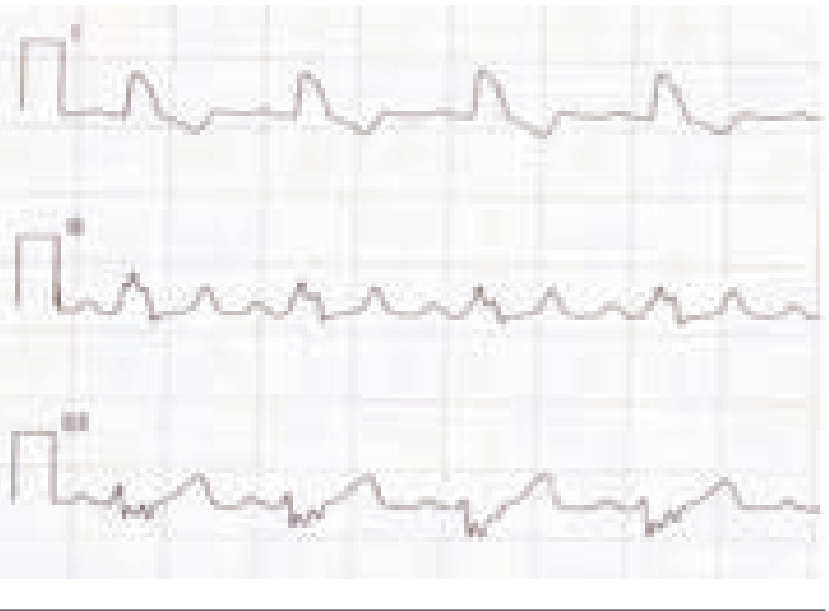

Figure 5. A) Wolff-Parkinson-White (WPW) conditions; B) left bundle brunch block. 
tigated, first of all using prolonged ECG monitoring. There is an ECG presentation which is highly suggestive for atrioventricular reentrant tachycardia or reciprocating tachycardia (AVRT).

Figure 5A is a typical example of WPW, a congenital syndrome involving abnormal conductive cardiac tissue between the atria and the ventricles that provides a pathway for a reentrant tachycardia circuit, in association with supraventricular tachycardia (SVT).

Features of WPW are short PR interval, QRS $<120 \mathrm{~ms}$ and delta waves (not to be confounded with SR and LBBB, Figure 5B). ${ }^{24}$

Clinical advice (Figure 5): Careful risk assessment with prolonged ECG monitoring, stress testing and electrophysiological study.

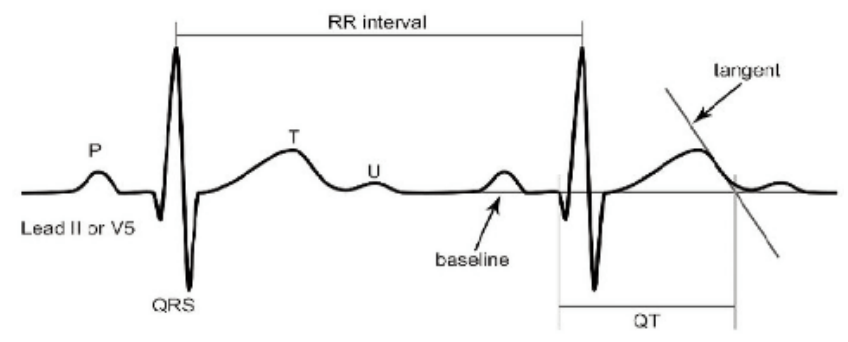

Figure 6. Intersection between isoelectric line and the tangent of the descending T-wave part (maximum slope intercept method).

\section{A}

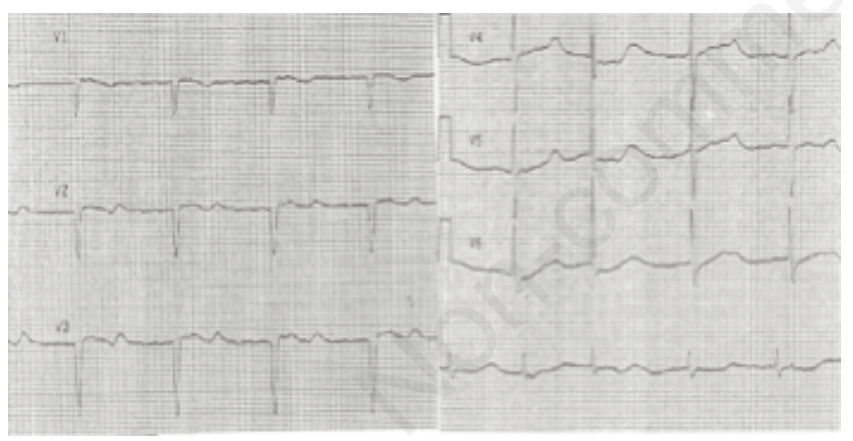

C

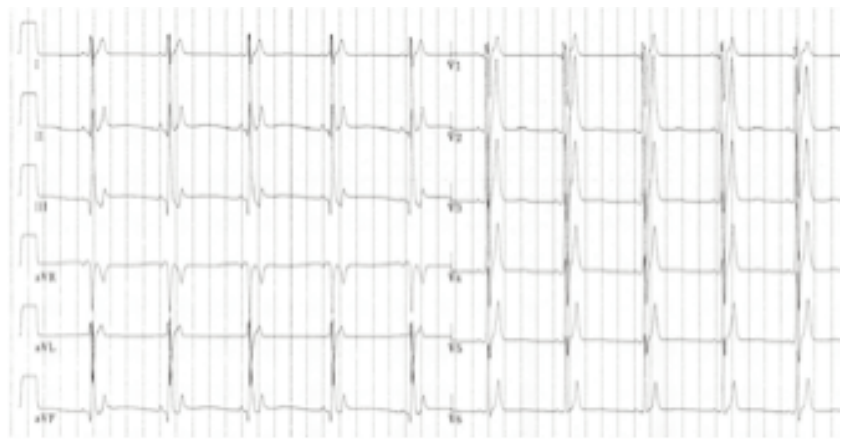

\section{QT duration abnormalities}

Long QT syndrome (LQTS) is a genetic or drug-induced disorder which affects repolarization of the cardiomyocytes. This results in an increased risk of torsade de pointes which can result in loss of consciousness, drowning or sudden death. Significant pathologic QTc intervals include values $>480 \mathrm{~ms}$, QTc durations of $>500 \mathrm{~ms}$ are highly associated with sudden cardiac death in patients with syncope. Pay attention to patients treated with amiodarone, sotalol, psychiatric drugs, antibiotics (especially macrolides and quinolones which are often used) and ondansetron. Precipitating factors can be electrolyte disorders like hypokalaemia, hypocalcaemia, hypomagnesaemia in vomiting, diarrhoea or other metabolic conditions. For a correct measurement of the QT interval it is important to pay attention at the U-wave. If the QT interval involves a $U$-wave or there is a notched T-wave, the U-wave takes part in the measurement. If the U-wave is separated (with clear space in the isoelectric line between $\mathrm{T}$ and $\mathrm{U}$ wave), it has not to be involved in the measurement of QT interval. The method to clarify this is the intersection between isoelectric line and the tangent of the descending T-wave part (maximum slope intercept method) (Figure 6).

Clinical advice (Figure 7A and B): 74-year-old male, affected by hypertension treated with ACE-inhibitor and thiazide diuretic, permanent atrial fibrillation treated with digitalis, depression treated using two non-tricyclic antidepressants. The patient was admitted because of a sudden syncopal episode in supine position, the blood tests showed hypokalaemia $(2 \mathrm{mEq} / \mathrm{l})$. In the clinical evaluation the most important point regards the medication of the patient. This patient is at high risk of sudden death. Hospitalization and continuous ECG monitoring are mandatory. ${ }^{25,29,38}$

This happened in the following hours during ECG monitoring: a torsade de pointes, which typically occurs in long QT conditions. It is characterized by continuous axis variation, and can be self-

\section{B}
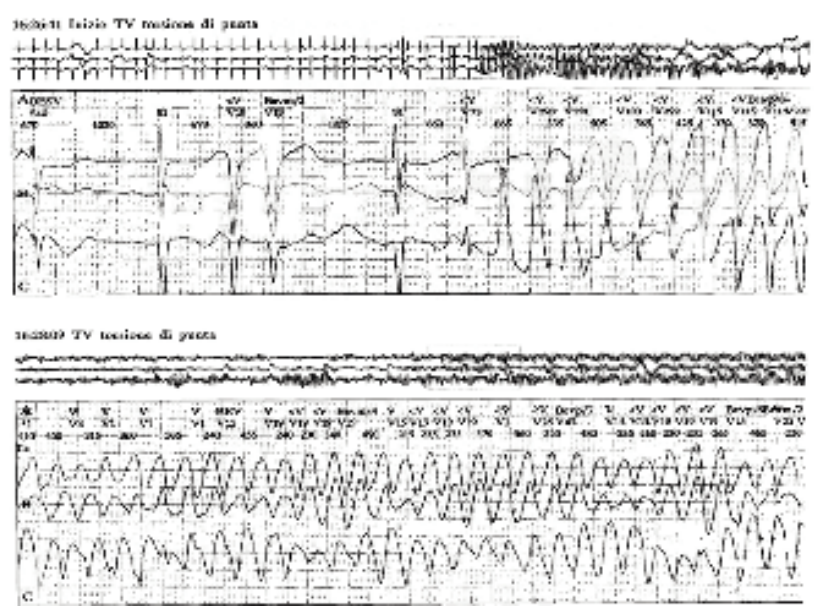

Figure 7. A) QT: $600 \mathrm{msec}$ QTc: $537 \mathrm{msec}$; the QT interval is particularly prolonged and most likely the cause of syncope; $B$ ) torsade de pointes, which typically occurs in long QT conditions, is characterized by continuous axis variation, and can be self-limiting. Often it can degenerate in ventricular fibrillation; C) the same careful management should be guaranteed for patients admitted with syncope and evidence of short QT interval. 
limiting. Often it can degenerate in ventricular fibrillation (Figure 7B). The same careful management should be guaranteed for patients admitted with syncope and evidence of short QT interval. Short QT syndrome is an inherited cardiac channelopathy characterized by an abnormally short QT interval and increased risk of ventricular fibrillation. Diagnosis is based on the evaluation of symptoms, patient's family history for sudden cardiac death and

A

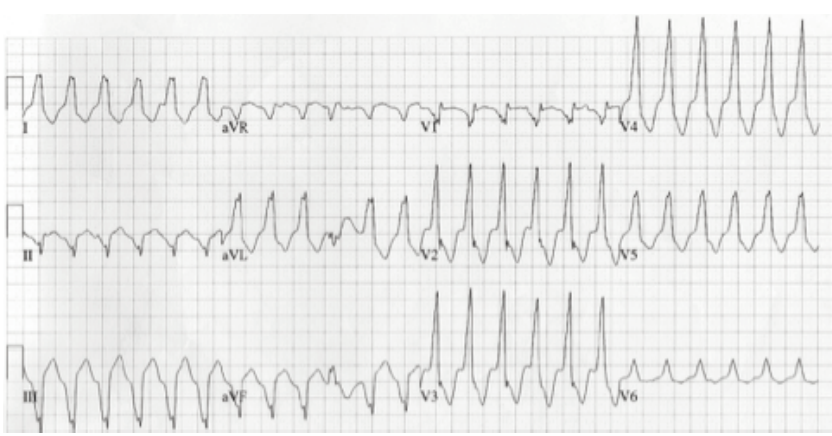

C

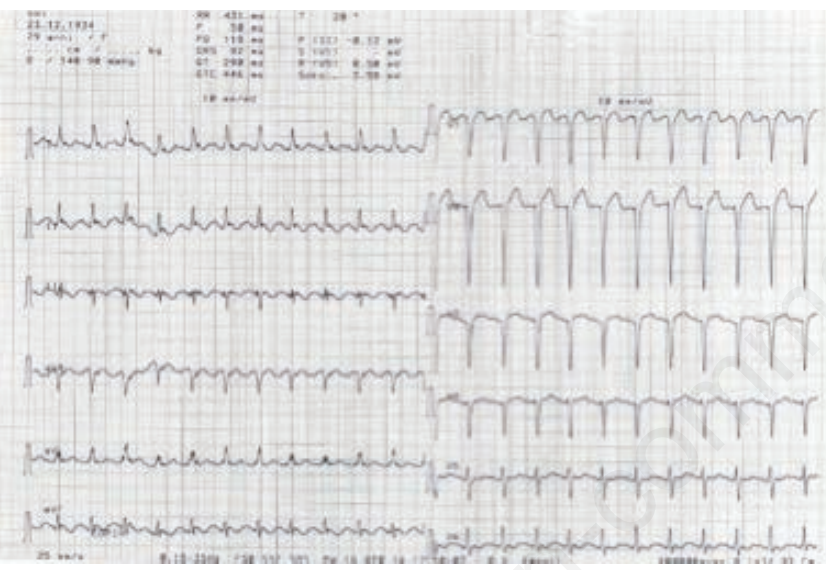

$\mathbf{E}$

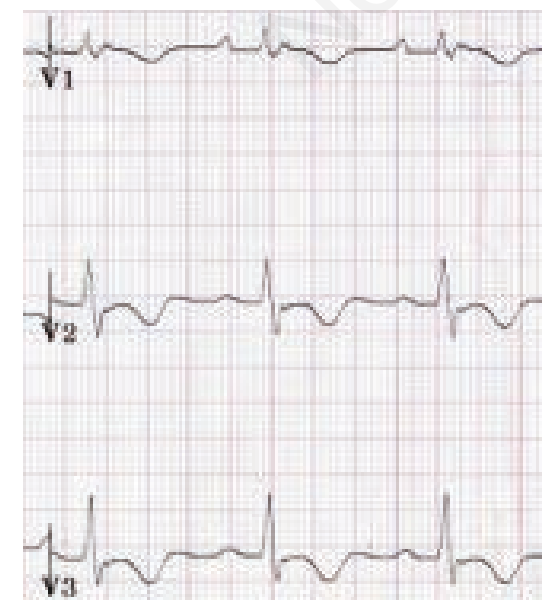

12-lead ECG. ${ }^{26}$ ICD is the first line therapeutic strategy (Figure 7C).

Diagnostic criteria for short QT syndrome are: i) QTc $\leq 330$ $\mathrm{ms}$; ii) QTc $<360 \mathrm{~ms}$ in the presence of one or more of the following elements: a) Pathogenetic mutation; b) Family history of short QT syndrome; c) Family history of sudden death $<40$ aa; d) VT or $\mathrm{VF}$ in absence of organic cardiopathy.

B

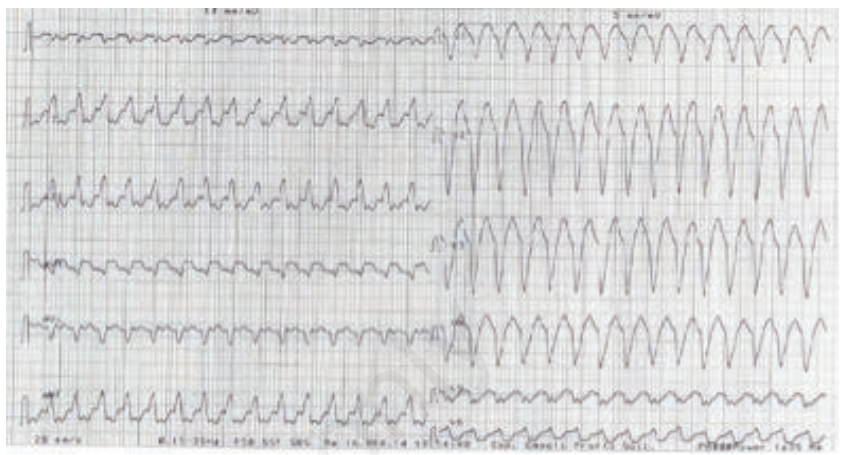

D

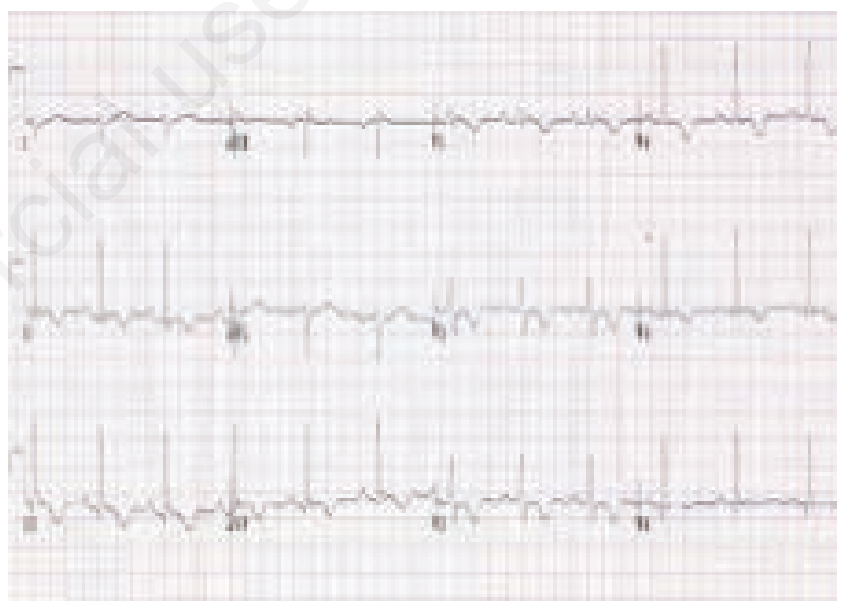

$\mathbf{F}$

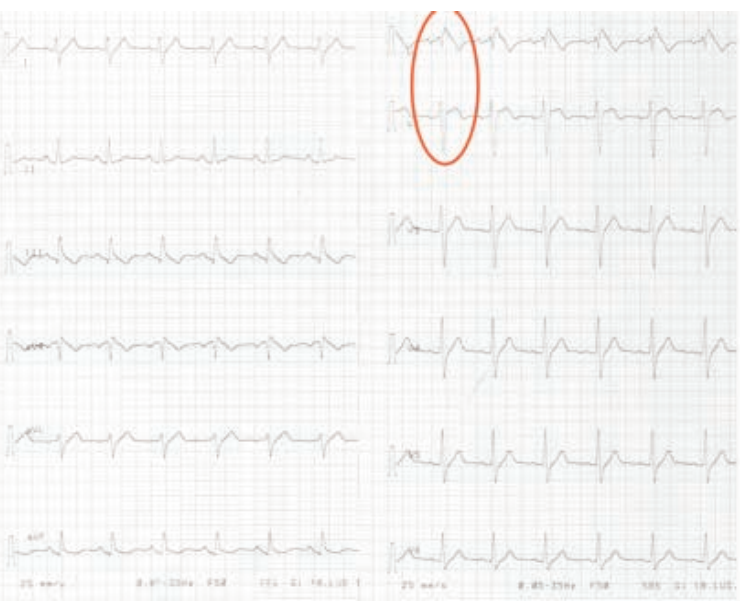

Figure 8. A) the evidence of AV dissociation means to find out a P-wave dissociated from the ventricular activity (you can see it in V1 derivation, in the last two beats); B) typical example of wide complex tachycardia; C) The transformation of QRS from wide to narrow QRS after e.v. adenosine. If adenosine does not influence the arrhythmia, the VT as diagnosis is confirmed; $\left.{ }^{30-35} \mathrm{D}\right)$, E) negative T-wave in precordial derivations; F) Type-1 Brugada pattern, characterized by coved ST-segment elevation V1-V2. 


\section{Wide complex tachycardia}

During wide complex tachycardia (HR > 100/min, QRS > $120 \mathrm{~ms}$ ) the differentiation between supraventricular and ventricular origin of the arrhythmias is important to guide therapy. Several algorithms have been developed to aid in this differentiation.

The evidence of a fusion beat or/and the AV dissociation establishes the diagnosis of VT. The fusion beat is a fusion in the ventricular depolarization between the VT and a rare SR beat, which is able to overstep the AVN and give a contribution in a part of ventricular depolarization (fourth beat in aVR, aVL and aVF derivation). The evidence of $\mathrm{AV}$ dissociation means to find out a P-wave dissociated from the ventricular activity (you can see it in V1 derivation, in the last two beats). In Figure 8A there are both features.

A third feature is the capture beat, which consists in a normally conducted P-wave followed by a QRS with normal duration.

A transoesophageal detection of atrial activity would allow to confirm AV dissociation, but it could be difficult to organize a procedure like this in the Emergency Department. A useful trick to unhide the nature of arrhythmias can be the use of adenosine, a medical treatment with very short life of few seconds, blocking the AVN.

The ECG showed in Figure 8B is a typical example of wide complex tachycardia, in which the diagnosis is very difficult considering the impossibility to find out the two characteristics mentioned before. If adenosine produces a modulation in AV conduction as in Figure $8 \mathrm{C}(2: 1,3: 1,4: 1 \ldots)$, there is an underlying supraventricular arrhythmia with aberrant conduction. ${ }^{30-35}$

Figure $8 \mathrm{D}$ and $\mathrm{E}$ show the negative $\mathrm{T}$-wave in precordial derivations. It is possible to identify a pathognomonic feature of right ventricular arrhythmogenic cardiomyopathy in V1 derivation at the end of QRS: the epsilon wave.

In a patient affected by syncope, the clinical and ECG features put him at high risk of sudden death. Clinical advice: pharmacological treatment or RF-Ablation could be useful to reduce the recurrences, but in context of high risk of sudden death, the ICD represents first line therapy. ${ }^{8,27,28,36,37}$

Figure 8F: type-1 Brugada pattern, characterized by coved STsegment elevation V1-V2.

In case of symptoms related to this ECG, we talk about Brugada Syndrome: a genetic condition that results in abnormal electrical activity within the heart, increasing the risk of sudden cardiac death. The condition is often inherited from a person's parent with about a quarter of people having a family history. Some case may be due to a new mutation or certain medications. The most commonly involved gene is SCN5A which codes for the cardiac sodium channel. Diagnosis is typically made by ECG.

Table 1. Major ECG findings suggesting arrhythmic syncope. Patients with syncope and one or more of this ECG characteristics are considered at high risk. ${ }^{1-8}$

Major ECG criteria suggesting arrhythmic syncope

Acute ischaemia

Q- Waves consistent with ischaemic heart disease

AV- Block II type Mobitz II or higher

Atrial fibrillation $<40 \mathrm{bpm}$

Persistent sinus bradycardia $<40 \mathrm{bpm}$

Repetitive sinoatrial block or sinus pauses $>3 \mathrm{~s}$ in waking hours

Bundle branch blocks

Intraventricular conduction disturbances

Signs of ventricular hypertrophy (Sokolow-Lyon Index $>35 \mathrm{~mm}$ )

Sustained or non-sustained ventricular tachycardia

Implanted cardiac device malfunction

ST- Segment elevation of Brugada I type-pattern

QTc $>460 \mathrm{~ms}$ indicating Long-QT Syndrome

Table 2. Minor criteria which put the patient at high risk profile if there is a history suggesting an arrhythmic syncope. ${ }^{7-9}$

Minor criteria suggesting arrhythmic syncope

AV-Block I ${ }^{\circ}$ with markedly prolonged AV- Interval or AV-Block II ${ }^{\circ}$ Mobitz

Asymptomatic inappropriate sinus bradycardia (40-50bpm)

Slow atrial fibrillation with 40-50bpm

Paroxysmal supraventricular tachycardia or atrial fibrillation

Pre-excited QRS complex

Short QTc interval $(<340 \mathrm{~ms})$

Atypical Brugada patterns

Negative T-waves in right precordial leads, epsilon waves suggesting arrhythmogenic right ventricular cardiomyopathy (ARVC)
A

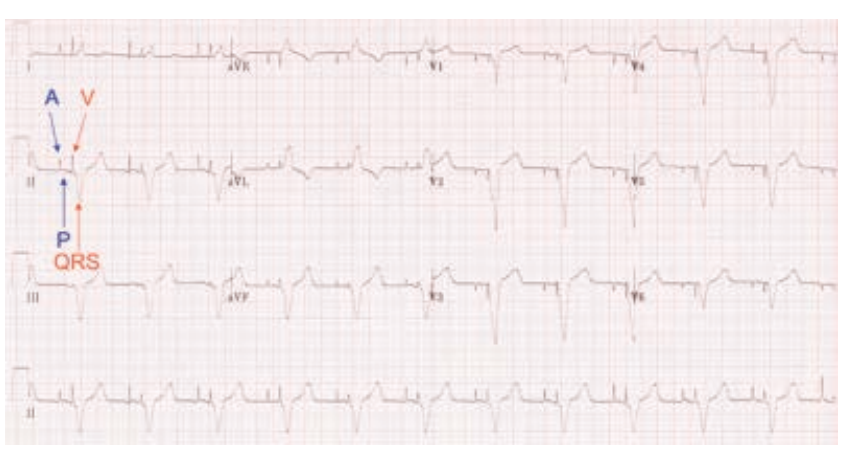

B

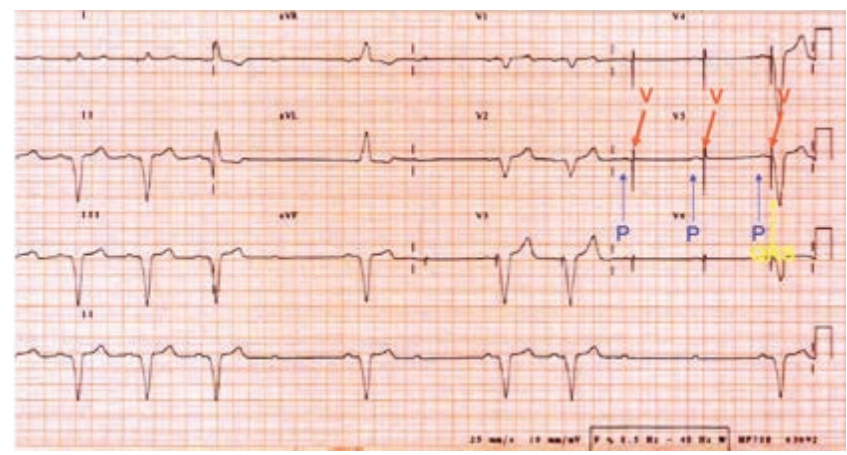

Figure 9. A) normal function of a pacemaker in sequential modality; B) pacemaker malfunction. 
Table 3. Red flag ECG criteria which suggest a likely arrhythmic syncope.

Sinus bradycardia $<40 \mathrm{bpm}$ in waking hours, recurrent sinoatrial blocks or sinus arrest $>3 \mathrm{~s}$

Second degree AV Block Mobitz Type 2 and third degree AV block, alternating bundle branch block

Ventricular or supraventricular paroxysmal tachycardia

PM and ICD malfunction with evidence of pauses

However, the abnormalities may not be consistently present. Medications such as ajmaline may be used to reveal the ECG changes. Fever can unmask the ECG Brugada pattern. Similar ECG patterns may be seen in certain electrolyte disturbances or due to a reduced blood supply to the heart.

Clinical advice: risk stratification in individuals with type 1 Brugada ECG pattern for primary prevention of sudden death is an unsolved issue. Patients with unexplained Syncope and evidence of type 1 Brugada ECG must be thoroughly investigated. Verify the family history of sudden death and perform an electrophysiologic study for the induction of ventricular arrhythmias. According to a consensus statement of experts the presence of two out of three criteria (unexplained syncope, family history of sudden death and induction of ventricular arrhythmias) represent an indication for ICD implantation. Anyway we suggest to monitor (with Implantable Loop Recorder) patients with unexplained syncope and type 1 Brugada ECG pattern. ${ }^{39-43}$

Supraventricular and ventricular tachycardia are suggestive of cardiac syncope in class 1 according to the guidelines of the European Society of Cardiology. Pharmacologic treatment or catheter ablation are indicated as first line therapy. In case of ventricular arrhythmias an accurate risk stratification of sudden death, which aims to verify the indication for an ICD implantation, is necessary.

\section{Device malfunction}

Pacemaker and ICD defects in patients affected by syncope are not uncommon.

Figure 9A: normal function of a pacemaker in sequential modality (synchronized atrial and ventricular pacing): atrial spikes generate an atrial depolarization and the ventricular spikes produce a ventricular depolarization, with wide QRS as as consequence of the fact that the ventricular catheter is located in apical position.

Figure 9B: pacemaker malfunction. The device can recognize the P-wave, but the ventricular spike is not followed by any depolarization (QRS complex): there is a working detection of the atrial catheter and a pacing defect of the ventricular catheter. This condition produces an asystolic pause which is cause of the syncope.

Clinical advice: all patients with previous pacemaker or ICD implantation affected by syncope must undergo a device control to verify its proper function.

\section{Conclusions}

An accurate clinical evaluation of patients affected by syncope involves the clinical history, physical examination, blood pressure measurement and careful ECG interpretation (Table 3). The presence of an abnormal ECG classifies the patient at moderate or high risk. This implies the necessity to perform further diagnostic procedures or to decide for a specific cardiologic treatment.

\section{References}

1. Quinn J, McDermott D, Stiell I, et al. Prospective validation of the San Francisco Syncope Rule to predict patients with serious outcomes. Ann Emerg Med 2006;47:448-54.

2. Colivicchi F, Ammirati F, Melina D, OESIL (Osservatorio Epidemiologico sulla Sincope nel Lazio) Study Investigators. Development and prospective validation of a risk stratification system for patients with syncope in the emergency department: the OESIL risk score. Eur Heart J 2003;24:811-9.

3. Del Rosso A, Ungar A, Maggi R, et al. Clinical predictors of cardiac syncope at initial evaluation in patients referred urgently to a general hospital: the EGSYS score. Heart 2008;94:1620-6.

4. Quinn JV, Stiell IG, McDermott DA, et al. Derivation of the San Francisco Syncope Rule to predict patients with short-term serious outcomes. Ann Emerg Med 2004;43:224-32.

5. Brignole M, Moya A, de Lange FJ, et al. 2018 ESC Guidelines for the diagnosis and management of syncope. The Task Force for the diagnosis and management of syncope of the European Society of Cardiology (ESC) developed with the special contribution of the European Heart Rhythm Association (EHRA). Eur Heart J 2018;00:1-69.

6. Reed MJ, Newby DE, Coull AJ, et al. The ROSE (Risk Stratification Of Syncope in the Emergency department) study. J Am Coll Cardiol 2010;55:713-21.

7. Costantino G, Perego F, STePS Investigators, et al. Short- and long-term prognosis of syncope, risk factors, and role of hospital admission: results from the STePS (Short-Term Prognosis of Syncope) study. J Am Coll Cardiol 2008;51:276-83.

8. Priori SG, Blomstrom-Lundqvist C, Mazzanti A. 2015 ESC Guidelines for the management of patients with ventricular arrhythmias and the prevention of sudden cardiac death: The Task Force for the Management of Patients with Ventricular Arrhythmias and the Prevention of Sudden Cardiac Death of the European Society of Cardiology (ESC). Endorsed by: Association for European Paediatric and Congenital Cardiology (AEPC). Eur Heart J 2015;36:2793-867.

9. Sheldon R, Rose S, Connolly S, et al. Diagnostic criteria for vasovagal syncope based on a quantitative history. Eur Heart J 2006;27:344-50.

10. Bahrat K. Sinus node disfunction workup. Available from: https://emedicine.medscape.com/article/158064-workup. Accessed: 24.2.2017.

11. Laroussi L. Atrioventrucular conduction disease and block. Cardiac Electrophysiol Clin 2014. Available from: https://www.cardiacep.theclinics.com/article/S18779182(14)00058-6/pdf.

12. Bellucci F. Antiarrithmic benefits of dual chamber stimulation with rate-response in patients with paroxismal atrial fibrillation and chronotropic incompetence: a prospective, multicenter study. EP Europace 1999. pp 220-225.

13. Brignole M, Sutton R, International Study on Syncope of 
Uncertain Etiology 2 Group, et al. Early application of an implantable loop recorder allows effective specific therapy in patients with recurrent suspected neurally mediated syncope. Eur Heart J 2006;27:1085-92.

14. Brignole M, Menozzi C, International Study on Syncope of Uncertain Etiology 3 Investigators, et al. Pacemaker therapy in patients with neurally mediated syncope and documented asystole: Third International Study on Syncope of Uncertain Etiology (ISSUE-3): a randomized trial. Circulation 2012;125:2566-71.

15. Brignole $\mathrm{M}$, Ammirati F, Arabia F, Quartieri F, Tomaino M, Ungar A, Lunati M, Russo V, Del 2743 Rosso A, Gaggioli G, Syncope Unit Project (SUP) Two Investigators. Assessment of a 2744 standardized algorithm for cardiac pacing in older patients affected by severe unpredictable 2745 reflex syncopes. Eur Heart J 2015;36:1529-1535.

16. Brignole M, Menozzi C, International Study on Syncope of Uncertain Etiology Investigators, et al. Mechanism of syncope in patients with bundle branch block and negative 2749 electrophysiological test. Circulation 2001;104:2045-50.

17. Linzer M, Yang EH, Estes NA, et al. Diagnosing syncope. Part 2: Unexplained syncope. Clinical Efficacy Assessment Project of the American College of Physicians. Ann Intern Med 1997; 127:76-86.

18. McAnulty JH, Rahimtoola SH, Murphy E. Natural history of "high-risk" bundle-branch block: final report of a prospective study. N Engl J Med 1982;307:137-43.

19. Moya A, Garcia-Civera R, Croci F, et al. Bradycardia detection in Bundle Branch Block (B4) study. Diagnosis, management, and outcomes of patients with syncope and bundle branch block. Eur Heart J 2011;32:1535-41.

20. Brignole M, Menozzi C, International Study on Syncope of Uncertain Etiology (ISSUE) Investigators, et al. Mechanism of syncope in patients with bundle branch block and negative 2749 electrophysiological test. Circulation 2001;104:2045-50.

21. Gronda M, Magnani A, Occhetta E, et al. Electrophysiological study of atrio-ventricular block and ventricular conduction defects. Prognostic and therapeutical implications. G Ital Cardiol 1984;14:768-73.

22. Kalscheur MM, Donateo P, Wenzke KE, et al. Long-term outcome of patients with bifascicular block and unexplained syncope following cardiac pacing. Pacing Clin Electrophysiol 2016;39:1126-31.

23. Scheinman MM, Peters RW, Suave MJ, et al. Value of the H$\mathrm{Q}$ interval in patients with bundle branch block and the role of prophylactic 2853 permanent pacing. Am J Cardiol 1982;50:1316-22.

24. Blomstroem-Lundqvist. Management of patients with supraventricular arrhythmias. J Am Coll Cardiol 2003;42: 1493-531.

25. Gibbs C. Predictors of mortality in high-risk patients with QT prolongation in a community hospital. Europace 2018;20:f99107.

26. Reviriego SM, Merino JL. Short QT Syndrome. J ESC Council Cardiol Pract 2010;9.

27. Elliott PM, Anastasakis A, Borger MA, et al. 2014 ESC Guidelines on diagnosis and management of hypertrophic cardiomyopathy: the Task Force for the Diagnosis and Management of Hypertrophic Cardiomyopathy of the European Society of Cardiology (ESC). Eur Heart J 2014;35:2733-79.

28. Corrado D, Calkins H, Link MS, et al. Prophylactic implantable defibrillator in patients with arrhythmogenic right ventricular cardiomyopathy/dysplasia and no prior ventricular fibrillation or sustained ventricular tachycardia. Circulation 2010;122:1144-52.

29. Liu JF, Jons C, Moss AJ, et al. International Long QT Syndrome Registry. Risk factors for recurrent syncope and subsequent fatal or near-fatal events in children and adolescents with long QT syndrome. J Am Coll Cardiol 2011;57:94150.

30. Spirito P, Autore C, Rapezzi C, et al. Syncope and risk of sudden death in hypertrophic cardiomyopathy. Circulation 2009;119:1703-10.

31. Spezzacatene A, Sinagra G, Merlo M, et al. Cardiomyopathy Registry. Arrhythmogenic Phenotype in Dilated Cardiomyopathy: Natural History and Predictors of LifeThreatening Arrhythmias. J Am Heart Assoc 2015;4:e002149.

32. Olde Nordkamp LR, Wilde AA, Tijssen JG, et al. The ICD for primary prevention in patients with inherited cardiac diseases: indications, use, and outcome: a comparison with secondary prevention. Circ Arrhythm Electrophysiol 2013;6:91-100.

33. Russo AM, Verdino R, Schorr C, et al. Occurrence of implantable defibrillator events in patients with syncope and nonischemic dilated cardiomyopathy. Am J Cardiol 2001;88:1444-1446.

34. Phang RS, Kang D, Tighiouart H, et al. High risk of ventricular arrhythmias in patients with nonischemic dilated cardiomyopathy presenting with syncope. Am J Cardiol 2006;97:41620.

35. Christiaans I, van Engelen K, van Langen IM. Risk stratification for sudden cardiac death in hypertrophic cardiomyopathy: systematic review of clinical risk markers. Europace 2010;12:313-21.

36. Corrado D, Wichter T, Link MS, et al. Treatment of arrhythmogenic right ventricular cardiomyopathy/dysplasia: an international task force consensus statement. Eur Heart J 2015;36:3227-37.

37. Bhonsale A, James CA, Tichnell C, et al. Incidence and predictors of implantable cardioverter-defibrillator therapy in patients with arrhythmogenic right ventricular dysplasia/cardiomyopathy undergoing implantable cardioverter-defibrillator implantation for primary prevention. J Am Coll Cardiol 2011;58:1485-96.

38. Jons C, Moss AJ, Goldenberg I, et al. Risk of fatal arrhythmic events in long QT syndrome patients after syncope. J Am Coll Cardiol 2010;55:783-8.

39. Probst V, Veltmann C, Eckardt L, et al. Long-term prognosis of patients diagnosed with Brugada syndrome: Results from the FINGER Brugada Syndrome Registry. Circulation 2010;121: 535-43.

40. Giustetto C, Schulze-Bahr E, Borggrefe M, et al. Long-term prognosis of patients diagnosed with Brugada syndrome: Results from the FINGER Brugada Syndrome Registry. Circulation 2010;121:635-43.

41. Conte G, Sieira J, Ciconte G, et al. Implantable cardioverterdefibrillator therapy in Brugada syndrome: a 20-year singlecenter experience. J Am Coll Cardiol 2015;65:879-88.

42. Olde Nordkamp LR, Vink AS, Wilde AA, et al. Syncope in Brugada syndrome: prevalence, clinical significance, and clues from history taking to distinguish arrhythmic from nonarrhythmic causes. Heart Rhythm 2015;12:367-75.

43. Giustetto C, Cerrato N, Ruffino E, et al. Etiological diagnosis, prognostic significance and role of electrophysiological study in patients with Brugada ECG and syncope. Int J Cardiol 2017;241:188-93. 